\title{
A functional SNP in ITIH3 is associated with susceptibility to myocardial infarction
}

\author{
Yusuke Ebana · Kouichi Ozaki · Katsumi Inoue · Hiroshi Sato · \\ Aritoshi Iida $\cdot$ Htay Lwin $\cdot$ Susumu Saito $\cdot$ Hiroya Mizuno $\cdot$ Atsushi Takahashi \\ Takahiro Nakamura · Yoshinari Miyamoto - Shiro Ikegawa · Keita Odashiro • \\ Masakiyo Nobuyoshi · Naoyuki Kamatani · Masatsugu Hori · Mitsuaki Isobe · \\ Yusuke Nakamura $\cdot$ Toshihiro Tanaka
}

Received: 3 November 2006/ Accepted: 1 December 2006/ Published online: 9 January 2007

(C) The Japan Society of Human Genetics and Springer 2006

\begin{abstract}
Myocardial infarction (MI) results from complex interactions of multiple genetic and environmental factors. To disclose genetic backgrounds of MI, we performed a large-scale, case-control association study using 52,608 gene-based single-nucleotide polymorphism (SNP) markers, and identified a candidate
\end{abstract}

Y. Ebana · K. Ozaki · H. Lwin · T. Tanaka $(\bowtie)$

Laboratory for Cardiovascular Diseases, SNP Research

Center, The Institute of Physical and Chemical Research

(RIKEN), 4-6-1 Shirokanedai, Minato-ku,

Tokyo 108-8639, Japan

e-mail: toshitan@ims.u-tokyo.ac.jp

Y. Ebana $\cdot$ M. Isobe

Department of Cardiovascular Medicine,

Tokyo Medical and Dental University, Tokyo, Japan

K. Inoue $\cdot$ K. Odashiro $\cdot$ M. Nobuyoshi

Department of Cardiology, Kokura Memorial Hospital,

Kitakyushu 802-8555, Japan

H. Sato $\cdot$ H. Mizuno $\cdot$ M. Hori

Department of Internal Medicine and Therapeutics,

Osaka University Graduate School of Medicine,

Suita, Japan

A. Iida $\cdot$ S. Saito $\cdot$ Y. Nakamura

Laboratory for Pharmacogenetics, SNP Research Center,

The Institute of Physical and Chemical Research (RIKEN),

Tokyo, Japan

A. Takahashi · T. Nakamura $\cdot$ N. Kamatani Laboratory for Statistical Analysis, SNP Research Center, The Institute of Physical and Chemical Research (RIKEN),

Tokyo, Japan

Y. Miyamoto $\cdot$ S. Ikegawa

Laboratory for Bone and Joint Disease, SNP Research Center, The Institute of Physical and Chemical Research (RIKEN), Tokyo, Japan
SNP located on chromosome 3p21.2-p21.1. Subsequent linkage-disequilibrium mapping indicated very significant association between MI and a SNP in exon 2 of the inter-alpha (globulin) inhibitor 3 gene (ITIH3; $\chi^{2}=24.88, P=6.1 \times 10^{-7}, 3,353$ affected individuals versus 3,807 controls). In vitro functional analyses showed that this SNP enhanced the transcriptional level of the ITIH3 gene. Furthermore, we found expression of the ITIH3 protein in the vascular smooth muscle cells and macrophages in the human atherosclerotic lesions, suggesting ITIH3 SNP to be a novel genetic risk factor of MI.

Keywords Functional analysis - Linkagedisequilibrium mapping - Myocardial infarction . Single-nucleotide polymorphism markers

\section{Introduction}

Coronary artery diseases, including myocardial infarction (MI), have been one of major leading causes of death in the developed countries (Ross 1999). Multiple lines of evidence have revealed several coronary risk factors contributing to the development of atherosclerosis (Libby 2002). Although each factor by itself seems partly under genetic control, a positive family history is an independent predictor (Shea et al. 1984), which implies genetic contribution to MI. Numerous reports based on family and/or twin studies have provided evidence for a genetic component in the etiology of MI (Marenberg et al. 1996). In recent years, candidate MI susceptibility genes were identified on several chromosome loci using linkage analysis (Wang et al. 2004) and/or single-nucleotide polymorphism (SNP) 
case-control association studies (Yamada et al. 2002; Ozaki et al. 2002, 2004, 2006; Helgadottir et al. 2004).

Inflammation is thought to contribute to atherosclerosis and increase the risk of MI (Libby 2002). It is a consequence of complex interactions among modified lipoproteins, monocyte-derived macrophages, $\mathrm{T}$ lymphocytes, and vascular smooth muscle cells (SMCs) from the vessel wall. Recent studies have shown the importance of chemoattractants, e.g., adhesion molecules (Cybulsky and Gimbrone 1991), chemokines (Boring et al. 1998), growth factors (Brogi et al. 1993), and proteolytic enzymes and their inhibitors (Galis et al. 1994), in atherosclerotic plaque formation and rupture.

Inter-alpha (globulin) inhibitor 3 (ITIH3), one of the constituents of plasma serine protease inhibitors, has been shown to be related to the proinflammatory process (Fries and Kaczmarczyk 2003). ITIH3 protein is characterized by its unique covalent binding to the chondroitin sulfate chain of bikunin proteoglycan (Zhuo et al. 2004). This complex, named pre-alpha trypsin inhibitor $(\mathrm{P} \alpha \mathrm{I})$ is synthesized by hepatocytes and released to the blood vessel upon stimulation of the proinflammatory cytokines (tumor necrosis factor or interleukin-1). Then, ITIH3 makes a complex with the locally synthesized hyaluronan (HA) and interacts with inflammatory cells (Fries and Kaczmarczyk 2003). ITIH3-HA complex has been reported to be involved in inflammatory diseases, including rheumatoid arthritis and inflammatory bowel diseases (Zhuo et al. 2004).

We report here identification of a significant association of a SNP in ITIH3 with MI through a largescale association study using approximately 50,000 gene-based SNPs. We also analyzed its functional significance indicating a possible role of this genetic variation in the pathogenesis of MI.

\section{Materials and methods}

\section{DNA samples}

The study included Japanese individuals with MI who were referred to the Osaka Acute Coronary Insufficiency Study group. The diagnosis of definite MI has been described previously (Ohnishi et al. 2000; Ozaki et al. 2002). The control subjects consisted of general populations recruited through several medical institutes in Japan. Clinical characteristics have been described previously (Ozaki et al. 2006). All subjects were Japanese and provided written informed consent to participation in the study or, if they were under
Table 1 Distribution of $P$ values in the first stage screening of 188 cases and 752 controls

\begin{tabular}{lcc}
\hline$P$ value & Number of SNPs & \\
\cline { 2 - 3 } & Recessive association & Dominant association \\
\hline$>0.01$ & 48,669 & 48,818 \\
$<0.01$ & 442 & 322 \\
$<0.001$ & 48 & 23 \\
$<0.0001$ & 5 & 4 \\
$<0.00001$ & 3 & 0 \\
\hline
\end{tabular}

20 years old, their parents gave consent according to the process approved by the Ethical Committee at the SNP Research Center, The Institute of Physical and Chemical Research (RIKEN), Yokohama.

\section{Genotyping}

Designs for polymerase chain reaction (PCR) primers, PCR experiments, DNA extraction, DNA sequencing, SNP discovery, genotyping of SNPs and statistical analysis have been described previously (Ohnishi et al. 2001; Ozaki et al. 2002).

\section{Haplotype block}

We used Haploview software for the identification of haplotype. We adopted the solid spine of LD for analysis and extended spine if $D^{\prime}>0.90$. We defined strong LD if the one-sided upper $95 \%$ confidence boundary on $D^{\prime}$ was $>0.98$ and the lower boundary was $<0.80$. Conversely, we defined strong recombination pairs for which the upper confidence bound on $D^{\prime}$ was less than 0.90 .

\section{Luciferase assay}

DNA fragments corresponding to nt 642 of intron 1 to 54 of intron 2 of ITIH3 were amplified by PCR using genomic DNA as template, and cloned into pGL3promotor vector (Promega) in the $5^{\prime}-3^{\prime}$ orientation. For the SV40-SNP-luciferase construct for ITIH3 SNP and all constructs for ITIH1 SNP, double-stranded oligonucleotides (nt 695 of intron 1 to 21 of intron 2 for ITIH3 and nt 517 to 551 of intron 10 for ITIH1) were cloned into pGL3-promoter vector. We grew Jurkat cells and HepG2 cells (obtained from RIKEN Cell Bank; RCB0806, RCB1681, respectively) in RPMI1640 medium and Dulbecco's modified eagle medium (DMEM), respectively, supplemented with $10 \%$ fetal bovine serum. We then transfected cells (approximately $1 \times 10^{5}$ and $3 \times 10^{6}$ cells in HepG2 and Jurkat cells, respectively) with $1 \mu \mathrm{g}$ of either construct and 
Table 2 Association analysis of SNPs in the third stage screening

\begin{tabular}{|c|c|c|c|c|c|}
\hline Genotype & MI (\%) & $\mathrm{CO}(\%)$ & Statistical test & Allele frequency & Dominant model \\
\hline \multicolumn{6}{|l|}{ rs2286797 } \\
\hline GG & $2,022(60.3)$ & 2,094 (55.0) & $\chi^{2}$ & 24.88 & 20.49 \\
\hline GA & $1,161(34.6)$ & $1,449(38.1)$ & $P$ value & $6.1 \times 10^{-7}$ & $6.0 \times 10^{-6}$ \\
\hline AA & $170(5.1)$ & $264(6.9)$ & Odds ratio & 1.216 & 1.243 \\
\hline Total & $3,353(100)$ & $3,807(100)$ & $95 \%$ CI & $1.126-1.313$ & $1.131-1.365$ \\
\hline \multicolumn{6}{|l|}{$\mathrm{rs} 2301523^{\mathrm{a}}$} \\
\hline GG & 2,919 (84.3) & 3,364 (88.1) & $\chi^{2}$ & 22.71 & 22.37 \\
\hline GA & $528(15.2)$ & 445 (11.7) & $P$ value & $1.9 \times 10^{-6}$ & $2.3 \times 10^{-6}$ \\
\hline AA & $17(0.5)$ & $10(0.3)$ & Odds ratio & 1.362 & 1.38 \\
\hline Total & $3,464(100)$ & $3,819(100)$ & $95 \%$ CI & $1.199-1.547$ & $1.207-1.578$ \\
\hline \multicolumn{6}{|l|}{ rs2074396 } \\
\hline $\mathrm{CC}$ & $1,354(40.3)$ & $1,523(40.5)$ & $\chi^{2}$ & 0.00 & 0.00 \\
\hline $\mathrm{CA}$ & $1,557(46.4)$ & $1,740(46.2)$ & $P$ value & 0.95 & 0.98 \\
\hline AA & 446 (13.3) & 501 (13.3) & Odds ratio & 1.002 & 1.002 \\
\hline Total & $3,357(100)$ & $3,764(100)$ & $95 \%$ CI & $0.936-1.073$ & $0.874-1.149$ \\
\hline \multicolumn{6}{|l|}{ rs989437 } \\
\hline $\mathrm{AA}$ & $2,122(65.8)$ & $2,396(64.0)$ & $\chi^{2}$ & 1.96 & 0.07 \\
\hline GA & $971(30.1)$ & 1,188 (31.7) & $P$ value & 0.16 & 0.79 \\
\hline GG & $133(4.1)$ & $159(4.2)$ & Odds ratio & 1.062 & 1.032 \\
\hline Total & $3,226(100)$ & $3,743(100)$ & $95 \%$ CI & $0.976-1.155$ & $0.976-1.155$ \\
\hline \multicolumn{6}{|l|}{ rs2240999 } \\
\hline GG & $2,544(75.4)$ & $2,947(78.0)$ & $\chi^{2}$ & 8.06 & 4.23 \\
\hline GC & 767 (22.7) & 786 (20.8) & $P$ value & 0.0045 & 0.04 \\
\hline $\mathrm{CC}$ & $61(1.8)$ & $46(1.2)$ & Odds ratio & 1.155 & 1.495 \\
\hline Total & $3,372(100)$ & $3,779(100)$ & $95 \% \mathrm{CI}$ & $1.046-1.276$ & 1.017-2.199 \\
\hline \multicolumn{6}{|l|}{ rs2242421 } \\
\hline GG & $1,400(41.6)$ & 1,485 (41.6) & $\chi^{2}$ & 0.57 & 0.42 \\
\hline GA & $1,502(44.6)$ & $1,748(46.9)$ & $P$ value & 0.45 & 0.52 \\
\hline AA & 462 (13.7) & 492 (13.2) & Odds ratio & 1.027 & 1.046 \\
\hline Total & $3,364(100)$ & $3,725(100)$ & $95 \%$ CI & $0.959-1.100$ & 0.913-1.199 \\
\hline \multicolumn{6}{|l|}{ rs2242442 } \\
\hline GG & $1,072(32.0)$ & $1,143(30.6)$ & $\chi^{2}$ & 0.26 & 0.4 \\
\hline GA & 1,605 (47.9) & $1,868(50.0)$ & $P$ value & 0.61 & 0.53 \\
\hline AA & $672(20.1)$ & 728 (19.5) & Odds ratio & 1.017 & 1.038 \\
\hline Total & $3,349(100)$ & $3,739(100)$ & $95 \%$ CI & $0.952-1.087$ & $0.924-1.167$ \\
\hline \multicolumn{6}{|l|}{ rs2292428 } \\
\hline $\mathrm{TT}$ & $1,631(48.4)$ & $1,844(49.1)$ & $\chi^{2}$ & 0.51 & 0.39 \\
\hline $\mathrm{TC}$ & $1,425(42.3)$ & $1,580(42.1)$ & $P$ value & 0.48 & 0.53 \\
\hline $\mathrm{CC}$ & $313(9.3)$ & $333(8.9)$ & Odds ratio & 1.026 & 1.053 \\
\hline Total & $3,369(100)$ & $3,767(100)$ & $95 \%$ CI & $0.955-1.103$ & $0.896-1.238$ \\
\hline \multicolumn{6}{|l|}{ rs2290140 } \\
\hline $\mathrm{CC}$ & $1,810(54.9)$ & $2,099(56.7)$ & $\chi^{2}$ & 2.96 & 1.23 \\
\hline CT & $1,265(38.3)$ & $1,373(37.1)$ & $P$ value & 0.085 & 0.27 \\
\hline $\mathrm{TT}$ & $224(6.8)$ & $227(6.1)$ & Odds ratio & 1.069 & 1.114 \\
\hline Total & $3,299(100)$ & $3,699(100)$ & $95 \%$ CI & 0.991-1.154 & $0.921-1.348$ \\
\hline \multicolumn{6}{|l|}{ rs3748037 } \\
\hline $\mathrm{CC}$ & $1,604(47.5)$ & $1,796(47.8)$ & $\chi^{2}$ & 0.28 & 0.65 \\
\hline $\mathrm{CT}$ & $1,435(42.5)$ & $1,610(42.8)$ & $P$ value & 0.6 & 0.42 \\
\hline TT & $336(10.0)$ & $353(9.4)$ & Odds ratio & 1.019 & 1.067 \\
\hline Total & $3,375(100)$ & $3,759(100)$ & $95 \%$ CI & 0.949-1.094 & $0.912-1.248$ \\
\hline \multicolumn{6}{|l|}{ rs1043228 } \\
\hline $\mathrm{CC}$ & $3,205(95.2)$ & $3,623(96.0)$ & $\chi^{2}$ & 2.92 & 0.02 \\
\hline $\mathrm{CT}$ & $159(4.7)$ & $147(3.9)$ & $P$ value & 0.087 & 0.89 \\
\hline TT & $3(0.1)$ & $3(0.1)$ & Odds ratio & 1.214 & 1.121 \\
\hline Total & $3,367(100)$ & $3,773(100)$ & $95 \%$ CI & $0.972-1.516$ & $0.226-5.556$ \\
\hline \multicolumn{6}{|l|}{ rs220079 } \\
\hline TT & $1,046(30.9)$ & $1,240(32.9)$ & $\chi^{2}$ & 2.04 & 0.21 \\
\hline $\mathrm{TC}$ & $1,703(50.4)$ & $1,841(48.8)$ & $P$ value & 0.15 & 0.65 \\
\hline $\mathrm{CC}$ & 632 (18.7) & 689 (18.3) & Odds ratio & 1.049 & 1.028 \\
\hline Total & $3,381(100)$ & $3,770(100)$ & $95 \%$ CI & $0.982-1.121$ & $0.912-1.159$ \\
\hline \multicolumn{6}{|l|}{ rs2808707 } \\
\hline GG & $921(27.3)$ & $1,058(28.3)$ & $\chi^{2}$ & 1.99 & 2.04 \\
\hline
\end{tabular}


Table 2 Continued

\begin{tabular}{llllll}
\hline Genotype & MI $(\%)$ & CO $(\%)$ & Statistical test & Allele frequency & Dominant model \\
\hline GT & $1,660(49.3)$ & $1,861(49.7)$ & $P$ value & 0.16 & 0.15 \\
TT & $789(23.4)$ & $823(22.0)$ & Odds ratio & 1.049 & 1.084 \\
Total & $3,370(100)$ & $3,742(100)$ & $95 \%$ CI & $0.982-1.120$ & $0.970-1.212$ \\
rs3793136 & & & & 0.18 & 0.93 \\
TT & $3,113(92.5)$ & $3,510(92.7)$ & $\chi^{2}$ & 0.67 & 0.34 \\
TC & $249(7.4)$ & $275(7.3)$ & $P$ value & 1.038 & 2.252 \\
CC & $4(0.1)$ & $2(0.1)$ & Odds ratio & $0.873-1.233$ & $0.412-12.301$ \\
Total & $3,366(100)$ & $3,790(100)$ & $95 \%$ CI & & \\
\hline
\end{tabular}

${ }^{a}$ Reported by Ishii et al. (21)

Table 3 Power of screening strategy

\begin{tabular}{lllll}
\hline & First & Second & Third & Total \\
\hline Additive model & 0.25 & 0.45 & 0.90 & 0.10 \\
Dominant model & 0.39 & 0.76 & 0.99 & 0.29 \\
Recessive model & 0.41 & 0.57 & 0.97 & 0.23 \\
\hline
\end{tabular}

$0.1 \mu \mathrm{g}$ of $\mathrm{pRL}-\mathrm{TK}$ vector, an internal control for transfection efficiency, using FuGene transfection reagent (Roche). After $24 \mathrm{~h}$, we collected cells and measured luciferase activity using the Dual-Luciferase Reporter Assay System (Promega; Ozaki et al. 2002).

Electrophoretic mobility-shift assay

We prepared nuclear extracts from Jurkat cells, HCASMCs and HCAECs (Cambrex) as previously described, and then incubated them with three tandem copies of 16 oligonucleotides ( 8 of exon 2 to 2 of intron 3 of ITIH3) labeled with digoxigenen -11-ddUTP using the digoxigenin gel-shift kit (Roche). For competition studies, we pre-incubated nuclear extract with unlabeled oligonucleotide (100-fold excess) before adding digoxigenin-labeled oligonucleotide. We separated the protein-DNA complexes on a non-denaturing 7\% polyacrylamide gel in $0.5 \times$ Tris-Borate-EDTA buffer. We transferred the gel to nitrocellulose membrane and detected the signal with a chemiluminescent detection system (Roche) according to the manufacturer's instructions (Ozaki et al. 2002).

Immunohistochemistry

Tissue samples were obtained from patients with MI by elective directional coronary atherectory after obtaining informed consent. Immunohistochemical protocols were carried out as described previously using goat polyclonal anti-human ITIH3 IgG (Santa Cruz) (Minami et al. 2001; Ozaki et al. 2004).
Statistical analysis

We carried out statistical analyses for the association study, haplotype frequencies and Hardy-Weinberg equilibrium and calculation of $r^{2}$ as described elsewhere (Yamada et al. 2001). We calculated the total number of independent SNPs in this study to be 41,362 (the SNPs in LD, $r^{2}>0.80$, were considered as one SNP) and used this to correct the obtained $P$ value by the Bonferroni's correction $\left(P_{\mathrm{c}}\right)$. The result of luciferase assay were tested using Fisher's exact test (Statistica software, StatSoft), and mRNA stability data were tested using Student $t$ test.

\section{Results}

Association study

We first genotyped randomly-selected 188 MI patients and 752 general Japanese population, using a highthroughput multiplex PCR-Invader assay method (Ohnishi et al. 2001) using 52,608 gene-based tag SNPs selected from the JSNP database (Haga et al. 2002; Tsunoda et al. 2004). We successfully obtained the genotype information at 49,167 SNP loci and the distribution of $P$ values for these SNPs is summarized in Table 1 . We further genotyped SNPs that showed $P$ value of 0.01 or smaller with a larger panel of individuals (664 MI and 1,473 controls) as the second-stage screening. Through this screening, we found 14 loci revealing $P$ values of 0.001 or smaller, and further verified their associations with MI by genotyping 3,353 affected and 3,807 control individuals. Of two SNPs that we considered to have the statistically-significant association (Table 2), one SNP was located within MIAT (Ishii et al. 2006) and the other was present in exon 2 (rs2286797) of the ITIH3 gene on chromosome 3p21.2-p21.1 $\left(P=6.1 \times 10^{-7}\right.$; comparison of allele 
Table 4 Identified polymorphisms in ITIH1 and ITIH3

\begin{tabular}{|c|c|c|}
\hline Polymorphism position $^{a}$ & rs number & MAF $^{\mathrm{b}}$ \\
\hline \multicolumn{3}{|l|}{ ITIH1 } \\
\hline Intron $2188 \mathrm{G}>\mathrm{A}$ & - & 0.021 \\
\hline Intron $5646 \mathrm{~A}>\mathrm{T}$ & rs2302417 & 0.490 \\
\hline Intron $61327 \mathrm{G}>\mathrm{A}$ & - & 0.021 \\
\hline Intron $61507 \mathrm{~T}>\mathrm{C}$ & rs2710323 & 0.500 \\
\hline Intron 8 304-305 GTGCCGGGAGTAA/ins & rs3836493 & 0.486 \\
\hline Exon $101197 \mathrm{C}>\mathrm{G}, \mathrm{I} 399 \mathrm{M}$ & rs12638839 & 0.021 \\
\hline Intron $10238 \mathrm{C}>\mathrm{T}$ & rs2710322 & 0.259 \\
\hline Intron $10320 \mathrm{G}>\mathrm{A}$ & rs 3774354 & 0.472 \\
\hline Intron $10423 \mathrm{G}>\mathrm{A}$ & rs 3774355 & 0.471 \\
\hline Intron $10536 \mathrm{~A}>\mathrm{C}$ & rs3774356 & 0.261 \\
\hline Intron $1187 \mathrm{G}>\mathrm{A}$ & rs 2239551 & 0.492 \\
\hline Intron $1282 \mathrm{~T}>\mathrm{A}$ & rs2268023 & 0.492 \\
\hline Exon 14 1754A > T, E585V & rs678 & 0.489 \\
\hline Exon 14 1784A > G, E595R & rs1042779 & 0.492 \\
\hline Intron $1436 \mathrm{~A}>\mathrm{G}$ & rs2286799 & 0.041 \\
\hline Intron $1462 \mathrm{~A}>\mathrm{C}$ & rs2286798 & 0.487 \\
\hline Intron $15148 \mathrm{C}>\mathrm{G}$ & - & 0.023 \\
\hline Intron $15299 \mathrm{G}>\mathrm{C}$ & - & 0.022 \\
\hline Intron $18428 \mathrm{~T}>\mathrm{C}$ & rs2284351 & 0.492 \\
\hline Intron $181069 \mathrm{~T}>\mathrm{G}$ & rs4687550 & 0.483 \\
\hline Intron $181087 \mathrm{~T}>\mathrm{C}$ & rs4687551 & 0.483 \\
\hline Exon $192196 \mathrm{G}>\mathrm{A}, \mathrm{R} 732 \mathrm{R}$ & - & 0.041 \\
\hline Exon 19 2311C > T, R771W & - & 0.041 \\
\hline Intron $19224 \mathrm{~A}>\mathrm{C}$ & rs2270197 & 0.492 \\
\hline Intron $20347-348 \mathrm{G} / \mathrm{ins}$ & rs3216516 & 0.483 \\
\hline Intron $20525 \mathrm{~T}>\mathrm{C}$ & rs1076425 & 0.492 \\
\hline Intron $20591 \mathrm{~T}>\mathrm{C}$ & rs1075653 & 0.500 \\
\hline Exon $212547 \mathrm{~T}>\mathrm{C}$, S849S & rs9324 & 0.497 \\
\hline Intron $21121 \mathrm{~T}>\mathrm{C}$ & - & 0.005 \\
\hline \multicolumn{3}{|l|}{ ITIH3 } \\
\hline Promoter $-1254 \mathrm{G}>\mathrm{A}$ & rs4687654 & 0.489 \\
\hline Promoter $-905 \mathrm{C}>\mathrm{T}$ & rs2239699 & 0.487 \\
\hline Promoter $-217 \mathrm{C}>\mathrm{T}$ & - & 0.063 \\
\hline Promoter $-192 \mathrm{C}>\mathrm{T}$ & rs9881468 & 0.457 \\
\hline Exon 2 108G > A, P36P & rs2286797 & 0.249 \\
\hline Exon 4 291C > T, D291D & rs2240921 & 0.001 \\
\hline Intron $4150 \mathrm{C}>\mathrm{T}$ & rs 2240920 & 0.481 \\
\hline Intron $4418 \mathrm{C}>\mathrm{G}$ & rs2240919 & 0.482 \\
\hline Intron $7112 \mathrm{G}>\mathrm{A}$ & rs 2535629 & 0.474 \\
\hline Exon $9943 \mathrm{C}>\mathrm{A}, \mathrm{K} 943 \mathrm{Q}$ & rs3617 & 0.495 \\
\hline Intron $1124 \mathrm{C}>\mathrm{T}$ & - & 0.027 \\
\hline Intron $11192 \mathrm{C}>\mathrm{T}$ & rs736408 & 0.456 \\
\hline Intron $13851 \mathrm{~T}>\mathrm{C}$ & rs4481150 & 0.478 \\
\hline Intron $131033 \mathrm{~T}>\mathrm{C}$ & rs2710331 & 0.459 \\
\hline Intron $14377 \mathrm{~T}>\mathrm{C}$ & rs4687552 & 0.458 \\
\hline Intron $1939 \mathrm{G}>\mathrm{C}$ & rs2276813 & 0.006 \\
\hline Intron $1999 \mathrm{G}>\mathrm{A}$ & rs13059141 & 0.024 \\
\hline Intron $21327 \mathrm{C}>\mathrm{T}$ & rs 3815421 & 0.004 \\
\hline
\end{tabular}

- The variant was not included in the dbSNP database (build 126)

a Nucleotide numbering is according to the mutation nomenclature (den Dunnen and Antonarakis 2000)

b Minor allele frequency

frequency, Table 2). Even after Bonferroni's correction, this result was considered to be statistically significant $\left(P_{\mathrm{c}}<0.05\right)$. Through the calculation by FDR (Storey 2002) and the association was unlikely to be false positive $\left(q\right.$ value $\left.=8.86 \times 10^{-4}\right)$. Detection power of this strategy for association under the condition of odds ratio of 1.5 and MAF of 0.40 is shown in Table 3 .

Since another SNP(s) in this locus might confer a genetic risk of MI, we searched the HapMap database (http://www.hapmap.org; The international HapMap Consortium 2003) and found that ITIH3 as well as ITIH1, both of which belong to the ITIH family, were contained in the same haplotype block. Hence, we subsequently screened SNPs in the genomic sequences covering ITIH1 and ITIH3, except for those corresponding to repetitive sequences, by re-sequencing of genomic DNAs from 24 Japanese individuals. We identified a total of 31 SNPs and two insertion/deletion polymorphisms in ITIH1 and 19 SNPs in ITIH3 (Table 4). A comparison of these SNPs in the dbSNP database (The National Center for Biotechnology Information, USA) identified 9 of them (intron $2188 \mathrm{G}>\mathrm{A}$, intron 5 646A > T, intron $15148 \mathrm{C}>\mathrm{G}, 299 \mathrm{G}>\mathrm{C}$, exon 19 2196G > A; R732R, 2311C > T; R771W, intron 21 $327 \mathrm{C}>\mathrm{T}$ in ITIH1; 5' flanking region $-205 \mathrm{G}>\mathrm{A}$, intron $1124 \mathrm{C}>\mathrm{T}$ in ITIH3) to be novel as at the end of May 2006. Among the 50 SNPs we identified, we genotyped 38 SNPs with the minor allele frequencies of $10 \%$ or greater for $94 \mathrm{MI}$ patients and 94 controls to construct a detailed haplotype map in this region (Fig. 1a). Using Haploview software (http://www.hapmap.org), we identified one haplotype block with four common haplotypes that covered more than $90 \%$ of the Japanese population. We selected three SNPs, rs2710322, rs2239699, and rs2286797 as tag SNPs that represented this locus (arrows, Fig. 1b) and further examined the association of each of the two additional tag SNPs (rs2710322 and rs2239699) with MI. Comparison of genotypes of 3,464 individuals with MI and 3,819 controls at these SNP loci revealed no significant association of either of the two additional SNP with MI (Table 5).

Subsequent analysis of each of the four common haplotypes against all others indicated the significant association of haplotype 4 with MI. However, since this haplotype contained the A allele for rs2286797 and the remaining haplotypes contained the $G$ allele for it (Table 6), we considered that the haplotype association simply reflected the association of the single SNP (rs2286797).

We also investigated one SNP in ITIH1 (intron 10 536A > C; rs3774356) that revealed strong LD with rs2286797 SNP $\left(r^{2}=0.93\right.$, Fig. 1a) in the initial LD mapping. However, genotyping of the maximum number of samples at this SNP locus revealed an association with MI at a much weaker level $\left(\chi^{2}=19.19, P=1.2 \times\right.$ $10^{-5}$, comparison of allele frequency, Table 7), indicating that ITIH3 is a gene susceptible to MI. 
A

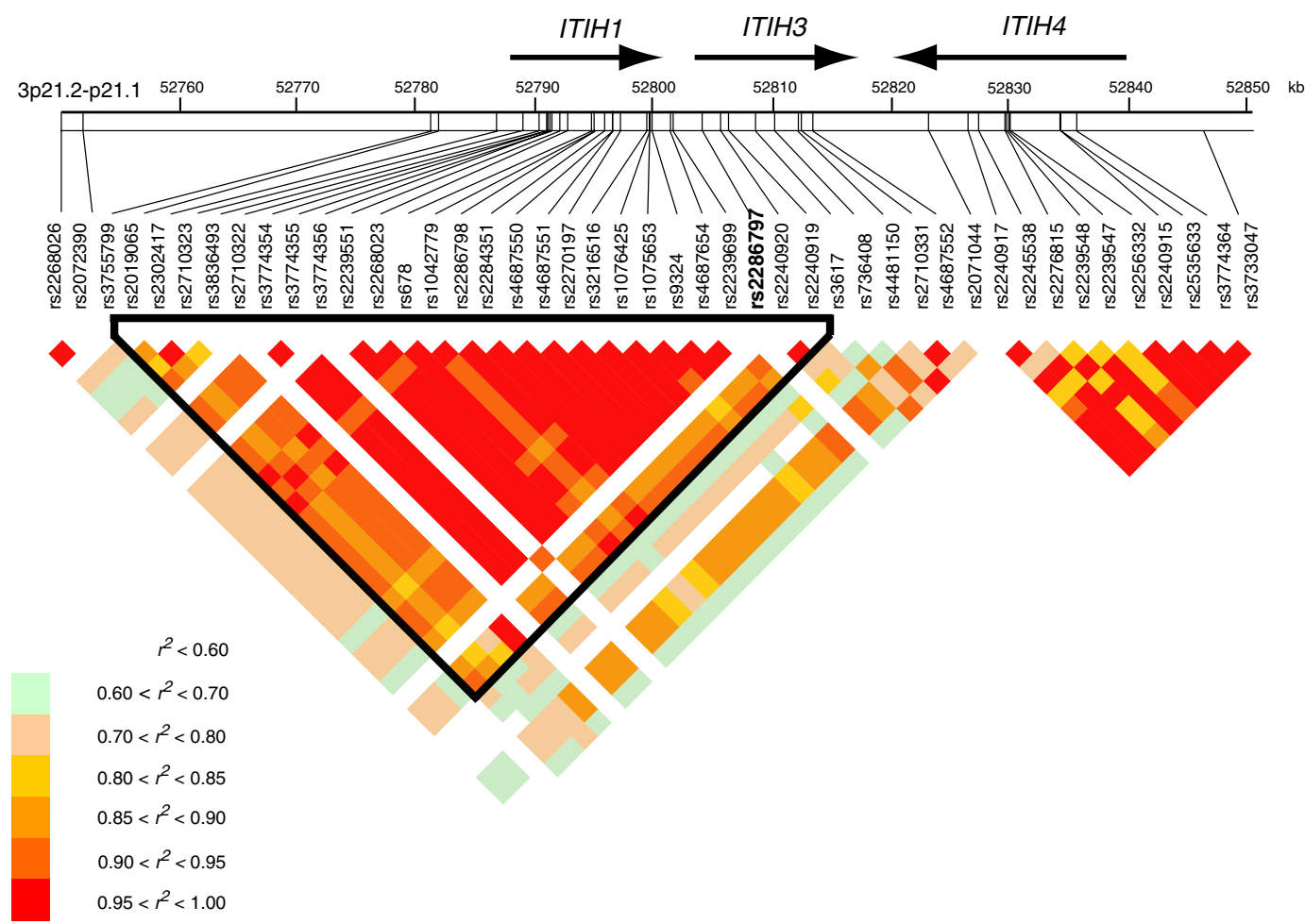

B

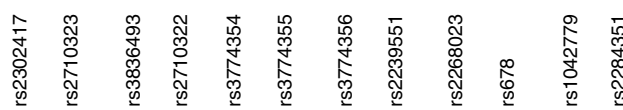

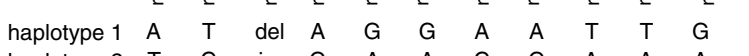

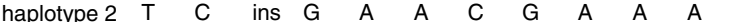

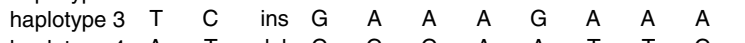

haplotype 4 A $T$ del $G$

tag SNP

Fig. 1 Polymorphism map and haplotype structure of ITIH1 and ITIH3 locus. a Map of SNPs (MAF $>10 \%$ ) in the ITIH1 and ITIH3 region, and pairwise LD coefficients $\left(r^{2}\right)$ among them.
The number of base-pair is based on genomic sequence (NC_000003.10) deposited in GenBank database. b Haplotype and tag SNPs in this region
Table 5 Association analysis of tag SNPs in the haplotype block

\begin{tabular}{lllll}
\hline Genotype & MI $(\%)$ & CO $(\%)$ & Statistical test & Dominant model \\
\hline rs2710322 & & & \\
GG & $1,889(55.7)$ & $2,107(57.1)$ & & \\
GA & $1,286(37.9)$ & $1,349(36.5)$ & $\chi^{2}$ & 1.33 \\
AA & $216(6.4)$ & $236(6.4)$ & $P$ value & 0.25 \\
Total & $3,391(100)$ & $3,692(100)$ & & \\
rs2239699 & $947(27.9)$ & $971(25.7)$ & & 7.23 \\
CC & $1,697(50.0)$ & $1,870(49.5)$ & $\chi^{2}$ & 0.0072 \\
CT & $752(22.1)$ & $939(24.8)$ & $P$ value & \\
TT & $3,312(100)$ & $3,749(100)$ & & \\
Total & & & & \\
\hline
\end{tabular}

Functional analyses of the exon 2 synonymous SNP in ITIH3

Since the most statistically-significant SNP did not substitute an amino acid of ITIH3 protein, we hypothesized that this synonymous SNP affected the transcriptional regulation, because several papers reported that some transcriptional factors bound to the exonic coding sequences of some genes and regulated their transcriptional level (Mori et al. 2002; Zhang 
Table 6 Haplotype association analysis using tag SNPs in the block

\begin{tabular}{llllllll}
\hline Haplotype ID & Case & Control & rs2710322 & rs2239699 & rs2286797 & $\chi^{2}$ & $P$ value \\
\hline Haplotype 1 & 0.275 & 0.259 & G & C & G & 4.84 \\
Haplotype 2 & 0.252 & 0.244 & G & T & G & 0.028 \\
Haplotype 3 & 0.25 & 0.24 & A & T & G & 1.33 \\
Haplotype 4 & 0.221 & 0.256 & G & T & 24.95 \\
\hline
\end{tabular}

Table 7 Association analysis of the SNP in ITIHI

\begin{tabular}{llllll}
\hline Genotype & MI (\%) & CO (\%) & Statistical test & Allele frequency & Dominant model \\
\hline rs3774356 & & & & & \\
AA & $2,035(59.9)$ & $2,093(55.7)$ & $\chi^{2}$ & 19.19 & 12.99 \\
AC & $1,194(35.2)$ & $1,402(37.3)$ & $P$ value & $1.2 \times 10^{-5}$ & $3.1 \times 10^{-4}$ \\
CC & $166(4.9)$ & $261(6.9)$ & Odds ratio & 1.188 & 1.189 \\
Total & $3,395(100)$ & $3,756(100)$ & $95 \%$ CI & $1.100-1.283$ & $1.082-1.306$ \\
\hline
\end{tabular}

et al. 2004; Ikeda et al. 2005). We constructed six different reporter plasmids (Fig. 2), each of which corresponded to a genomic fragment including the SNP, and performed a luciferase assay using Jurkat and HepG2 cells. The clones containing the DNA fragment corresponding to the $\mathrm{G}$ allele showed greater transcriptional activity in both HepG2 and Jurkat cells than those containing the A allele (Fig. 2a, b), indicating this SNP affects transcriptional level of ITIH3.

Using nuclear extracts from human coronary artery smooth muscle cells (HCASMCs), human coronary artery endothelial cells (HCAECs), and Jurkat cells originated from human $\mathrm{T}$ lymphocyte, all of which were considered to be important players in the pathogenesis of MI, we subsequently examined the presence of some nuclear factor(s) that might bind to oligonucleotides corresponding to genomic sequences of the $108 \mathrm{G}$ or $108 \mathrm{~A}$ alleles, although no known protein was predicted to bind to this DNA segment. When we used nuclear extracts from Jurkat cells (Fig. 2c), we observed two bands of different molecular weights in the lane corresponding to the $\mathrm{G}$ allele or the A allele, suggesting that two different nuclear proteins in Jurkat cells bound to each of the allele. However, this kind of difference was not observed when we used HCASMCs or HCAECs (data not shown).

\section{Expression of ITIH3 protein in atherosclerotic} lesion

To investigate whether ITIH3 protein was expressed in atherosclerotic plaque, we carried out immunohistochemical staining of human coronary atherectomy specimens with anti-ITIH3 antibody. As shown in Fig. 3, ITIH3 was detected in the macrophages, foam cells, and SMCs. Almost all the macrophages and foam cells were stained, some of which were aggregated around cholesterol crystals in intima. The SMCs in a deep layer of the vessel wall were stained more intensively.

\section{Discussion}

Through a large-scale, case-control association study and subsequent LD mapping, we identified ITIH3 as a strong candidate gene conferring one of the risk factors for MI. We have demonstrated that the SNP showing the strong association with MI is likely to influence the transcriptional activity of this gene. In addition, by means of electrophoretic mobility-shift assay, we found the difference in the binding affinity to the unidentified transcription factor(s) in lymphocyte-derived cell line (Jurkat cell) in an allele-specific manner, although this difference was not observed in HCASMCs and HCAECs. Through the allele-specific difference in the ITIH3 protein level by some stress responses, $\mathrm{T}$ lymphocytes could contribute to the process in atherosclerotic changes through its inflammatory functions and increase the risk of MI (Libby 2002).

In addition to the in vitro experimental data, we have shown that ITIH3 protein was abundantly accumulated in SMCs and macrophages in the intima of human atherosclerotic plaques while they were absent in quiescent or normal medial SMCs, implying that ITIH3 might play a critical role in the pathogenesis of atherosclerosis and subsequent myocardial infarction.

Although functional correlation of ITIH3 with the development, progression or rupture of atherosclerotic plaques remains to be clarified, several papers reported that the members and constituents of the I $\alpha \mathrm{I}$ family were detected in synovial fluid of patients with rheumatoid arthritis (Yingsung et al. 2003), in colo- 
A
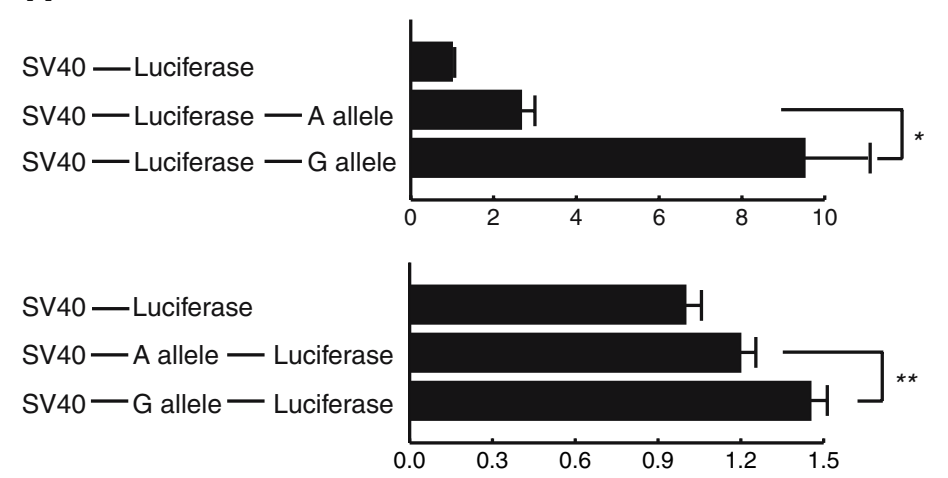

SV40 - Luciferase

A allele - SV40 — Luciferase

G allele - SV40 — Luciferase

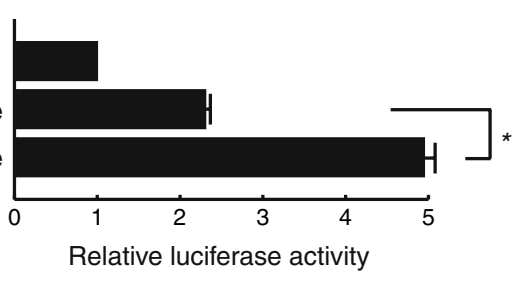

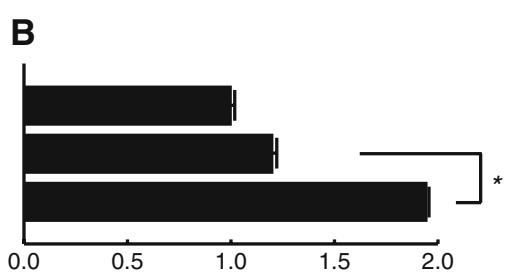
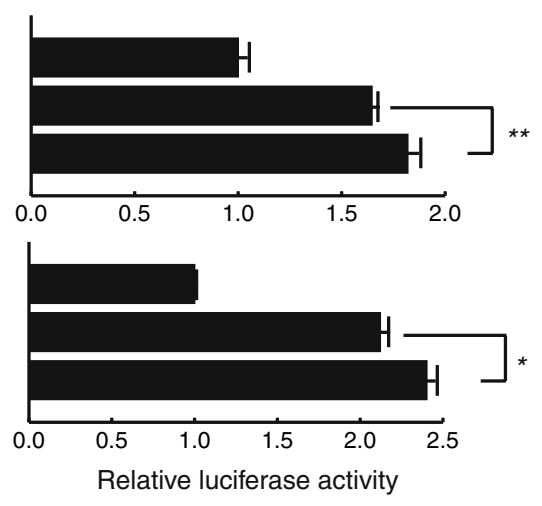

C

Competitor

Extract

$\begin{array}{llllll}- & - & - & - & + & + \\ - & - & + & + & + & +\end{array}$

SNP in exon 2 of ITIH3

G $A \quad G \quad A \quad G \quad A$

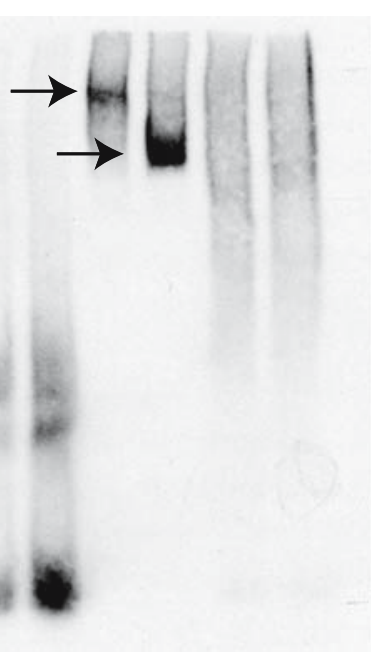

times independently. c Binding of unknown nuclear factors to exon 2 of ITIH3 in Jurkat cells. The experiment was repeated three times with similar results

attachment ligand for macrophages (Ross 1999) and lymphocytes (Jean et al. 2001). Since several recent reports also suggested that genes related to inflammation conferred risk of MI (Ozaki et al. 2002, 2004, 2006; Helgadottir et al. 2004), it is conceivable that this molecule plays an important role in the pathogenesis of MI through inflammatory response.

Although the detailed biological role of ITIH3 protein in the pathogenesis of atherosclerosis is still to 
Fig. 3 Expression of ITIH3 protein in coronary atherectomy specimen. a Most vascular SMCs in intimal layer and macrophages in deep layer are stained. Magnification $\times 37$. b Activated SMCs are migrated and proliferated in shallow layer in the vessel. Magnification $\times 70$. c Foam cells aggregate around cholesterol crystals. Magnification $\times 70$. d SMCs migrated from medial layer to intimal layer are stained, while those remained in medial layer are not. Magnification $\times 50$
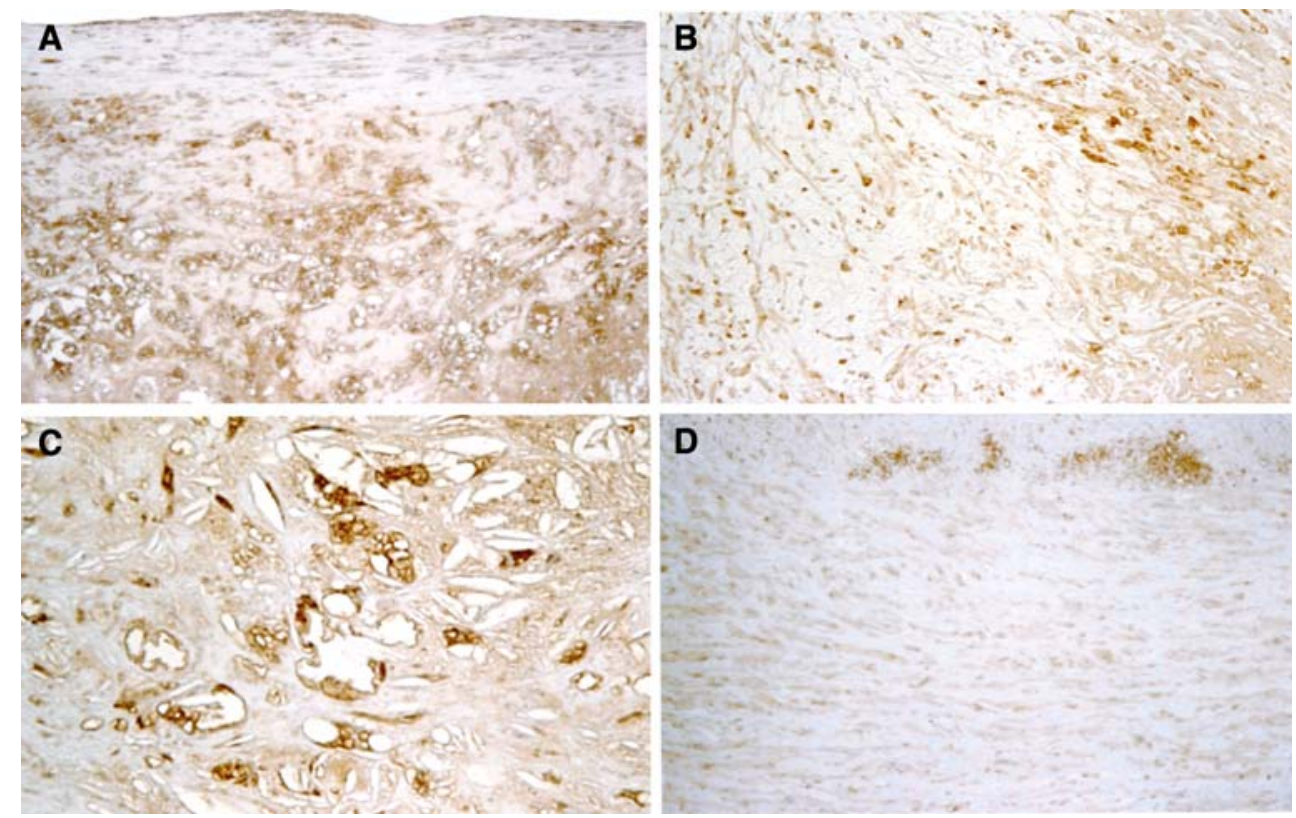

be clarified, we believe our findings would be an anchoring point for functional clarification of this gene and also provide a useful clue for development of novel diagnostic method, treatments and prevention for this common but serious disorder.

Acknowledgments We thank Maki Takahashi, Mayumi Yoshii, Saori Abiko, Wataru Yamanobe, Miyuki Omotezako, Yoko Ariji, Rumiko Ohishi, Makiko Watabe and Kaori Tabei and Saori Manabe for their assistance. We also thank all the other members of SNP Research Center, RIKEN and OACIS for their contribution to the completion of our study. We are also grateful to members of The Rotary Club of Osaka-Midosuji District 2660 Rotary International in Japan for supporting our study. This work was supported in part by three grants from the Takeda science foundation, the Uehara science foundation and the Japanese Millennium Project.

\section{References}

Balduyck M, Albani D, Jourdain M, Mizon C, Tournoys A, Drobecq H, Fourrier F, Mizon J (2000) Inflammtioninduced systemic proteolysis of inter- $\alpha$-inhibitor in plasma from patients with sepsis. J Lab Clin Med 135:188-198

Boring L, Gosling J, Cleary M, Charo IF (1998) Decreased lesion formation in CCR2-/- mice reveals a role for chemokines in the initiation of atherosclerosis. Nature 394:894-897

Brogi E, Winkles JA, Underwood R, Clinton SK, Alberts GF, Libby P (1993) Distinct pattern of expression of fibroblast growth factors and their receptors in human atheroma and nonatherosclerotic arteries. Association of acidic FGF with plaque microvessels and macrophages. $\mathbf{J}$ Clin Invest 92:2408-2418

Cybulsky MI, Gimbrone MA Jr (1991) Endothelial expression of a mononuclear leukocyte adhesion molecule during atherosclerosis. Science 251:788-791 den Dunnen JT, Antonarakis SE (2000) Mutation nomenclature extensions and suggestions to describe complex mutations: a discussion. Hum Mutat 15:7-12

de la Motte CA, Hascall VC, Calabro A, Yen-Lieberman B, Strong SA (1999) Mononuclear leukocytes preferentially bind via CD44 to hyaluronan on human intestinal mucosal smooth muscle cells after virus infection or treatment with poly(I:C). J Biol Chem 274:30747-30755

de la Motte CA, Hascall VC, Drazba J, Bandyopadhyay SK, Strong SA (2003) Mononuclear leukocytes bind to specific hyaluronan structures on colon mucosal smooth muscle cells treated with polyinosinic acid; polycytidylic acid. Am J Pathol 163:121-133

Fries E, Kaczmarczyk A (2003) Inter- $\alpha$-inhibitor, hyaluronan and inflammation. Acta Biochim Pol 50:735-742

Galis ZS, Sukhova GK, Lark MW, Libby P (1994) Increased expression of matrix metalloproteinases and matrix degrading activity in vulnerable regions of human atherosclerotic plaques. J Clin Invest 94:2493-2503

Haga H, Yamada R, Ohnishi Y, Nakamura Y, Tanaka T (2002) Gene-based SNP discovery as part of the Japanese Millennium Genome project; identification of 190,562 genetic variations in the human genome. J Hum Genet 47:605-610

Helgadottir A, Manolescu A, Thorleifsson G, Gretarsdottir S, Jonsdottir H, Thorsteinsdottir U, Samani NJ, Gudmundsson G, Grant SFA, Thorgeirsson G et al (2004) The gene encoding 5-lipoxygenase activating protein confers risk of myocardial infarction and stroke. Nat Genet 36:233-239

Ikeda S, Kurose K, Jinno H, Sai K, Ozawa S, Hasegawa R, Komamura K, Kotake T, Morishita H, Kamakura S et al (2005) Functional analysis of four naturally occurring variants of human constitutive androstane receptor. Mol Genet Metab 86:314-319

Ishii N, Ozaki K, Sato H, Mizuno H, Saito S, Takahashi A, Miyamoto Y, Ikegawa S, Kamatani N, Hori M, Saito S, Nakamura Y, Tanaka T (2006) Identification of a novel noncoding RNA, MIAT, that confers risk of myocardial infarction. J Hum Genet (in press) 
Jean L, Mizon C, Larsen WJ, Mizon J, Salier J (2001) Unmasking a hyaluronan-binding site of the $\mathrm{BX}_{7} \mathrm{~B}$ type in the $\mathrm{H} 3$ heavy chain of the inter- $\alpha$-inhibitor family. Eur $\mathrm{J}$ Biochem 268:544-553

Libby P (2002) Atherosclerosis in inflammation. Nature 420:868974

Marenberg EM, Risch N, Berkman LF, Floderus B, de Faire U (1996) Genetic susceptibility to death from coronary heart disease in a study of twins. N Engl J Med 330:1041-1046

Minami M, Kume N, Shimaoka T, Kataoka H, Hayashida K, Akiyama Y, Nagata I, Ando K, Nobuyoshi M, Hanyuu M, Komeda M, Yonehara S, Kita T (2001) Expression of SRPSOX, a novel cell-surface scavenger receptor for phosphatidylserine and oxidized LDL in human atherosclerotic lesions. Artrioscler Thromb Vasc Biol 21:1796-1800

Mori T, Anazawa Y, Iiizumi M, Fukuda S, Nakamura Y, Arakawa H (2002) Identification of the interferon regulatory factor 5 gene (IRF-5) as a direct target for p53. Oncogene 21:2914-2918

Ohnishi Y, Tanaka T, Yamada R, Suematsu K, Minami M, Fujii K, Hoki N, Kodama K, Nagata S, Hayashi T et al (2000) Identification of 187 single nucleotide polymorphisms (SNPs) among 41 candidate genes for ischemic heart disease in the Japanese population. Hum Genet 106:288-292

Ohnishi Y, Tanaka T, Ozaki K, Yamada R, Suzuki H, Nakamura Y (2001) A high-throughput SNP typing system for genomewide association studies. J Hum Genet 46:471-477

Ozaki K, Ohnishi Y, Iida A, Sekine A, Yamada R, Tsunoda T, Sato H, Sato H, Hori M, Nakamura $Y$ et al (2002) Functional SNPs in the lymphotoxin- $\alpha$ gene that are associated with susceptibility to myocardial infarction. Nat Genet 32:650-654

Ozaki K, Inoue K, Sato H, Iida A, Ohnishi Y, Sekine A, Sato H, Odashiro K, Nobuyoshi M, Hori M et al (2004) Functional variation in $L G A L S 2$ confers risk of myocardial infarction and regulates lymphotoxin- $\alpha$ secretion in vitro. Nature 429:72-75

Ozaki K, Sato H, Iida A, Mizuno H, Nakamura T, Miyamoto Y, Takahashi A, Tsunoda T, Ikegawa S, Kamatani N, Hori M, Nakamura Y, Tanaka T (2006) A functional SNP in PSMA6 confers risk of myocardial infarction in the Japanese population. Nat Genet 38:921-225

Ross R (1999) Atherosclerosis—an inflammatory disease. N Engl J Med 340:115-126
Shea S, Ottman R, Gabrieli C, Stein Z, Nichols A (1984) Family history as an independent risk factor for coronary artery disease. J Am Coll Cardiol 4:793-801

Storey JD (2002) A direct approach to false discovery rate. J R Stat Soc Ser B 64:479-498

The International HapMap Consortium (2003) The International HapMap Project. Nature 426:789-796

Tsunoda T, Lathrop GM, Sekine A, Yamada R, Takahashi A, Ohnishi Y, Tanaka T, Nakamura Y (2004) Variation of gene-based SNPs and linkage disequilibrium patterns in the human genome. Hum Mol Genet 13:1623-1632

Wang Q, Rao S, Shen GQ, Li L, Moliterno DJ, Newby LK, Rogers WJ, Cannata R, Zirzow E, Elston RC et al (2004) Premature myocardial infarction novel susceptibility locus on chromosome 1p34-36 identified by genomewide linkage analysis. Am J Hum Genet 74(2):262-271

Yamada R, Tanaka T, Unoki M, Nagai T, Sawada T, Ohnishi Y, Tsunoda T, Yukioka M, Maeda A, Suzuki K et al (2001) Association between a single-nucleotide polymorphism in the promoter of the human interleukin-3 gene and rheumatoid arthritis in Japanese patients, and maximum-likelihood estimation of combinatorial effect that two genetic loci have on susceptibility to the disease. Am J Hum Genet 68:674685

Yamada Y, Izawa H, Ichihara S, Takatsu F, Ishihara H, Hirayama H, Sone T, Tanaka M, Yokota M (2002) Prediction of the risk of myocardial infarction from polymorphisms in candidate genes. N Engl J Med 347:1916-1923

Yingsung $\mathrm{W}$, Zhuo L, Morgelin $\mathrm{M}$, Yoneda M, Kida D, Watanabe H, Ishiguro N, Iwata H, Kimata K (2003) Molecular heterogeneity of the SHAP-hyaluronan complex. J Biol Chem 278:32710-32718

Zhang EY, Fu DJ, Pak YA, Stewart T, Mukhopadhyav N, Wrighton SA, Hillgeren KM (2004) Genetic polymorphisms in human proton-dependent dipeptide transporter PEPT1: implications for the functional role of Pro586. J Pharmacol Exp Ther 310(2):437-445

Zhao M, Yoneda M, Ohashi Y, Kurono S, Iwata H, Ohnuki Y, Kimata K (1995) Evidence for the covalent binding of SHAP, heavy chains of inter- $\alpha$-trypsin inhibitor, to hyaluronan. J Biol Chem 270:26657-26663

Zhuo L, Hascall VC, Kimata K (2004) Inter- $\alpha$-trypsin inhitibor, a covalent protein-glycosaminoglycan-protein complex. J Biol Chem 279:38079-38082 